\title{
Review
}

\section{Oxygen free radicals, inflammation, and synovitis: the current status}

There has been an explosion of interest in the putative role of oxygen free radicals as agents of tissue damage in a vast number of diseases, ranging from cancer, through autoimmune conditions, to acute and chronic inflammatory disease. ${ }^{1}$ Indeed, oxygen free radicals have been implicated in the pathogenesis of virtually all known diseases-the aging process itself being no exception. Does this mean that radical reactions are an irrelevance-an epiphenomenon, or are radical reactions so fundamental to human biology that uncontrolled radical responses inevitably lead to disease?

\section{What is a free radical?}

Molecules achieve their stability by electron pairing and subsequent covalent bond formation. A free radical may be defined as an atom or molecule with one or more unpaired electrons, capable of independent existence. They are denoted by a superscipted dot $\mathbf{R}^{\prime}$, and may have a positive, negative, or neutral charge. Examples include the oxygen molecule, the hydrogen atom, and most transition metals. ${ }^{2}$ The unpaired electron(s) that characterises an oxygen free radical confers a high level of instability and thus a high chemical reactivity on the molecule. Consequently, oxygen free radicals only exist at very low steady state concentrations in vivo (from $\left.10^{-4}-10^{-9} \mathrm{~mol} / \mathrm{l}\right)$.

In aerobic organisms molecular oxygen $\left(\mathrm{O}_{2}\right)$ has an important role as an electron acceptor and has been shown to mediate a variety of free radical reactions within cells. It has an almost unique electron configuration with two electrons in its outer orbitals, both possessing the same spin quantum number $(\uparrow)(\uparrow)$. When $\mathrm{O}_{2}$ reacts with an atom or molecule with the more usual electron pair configuration $(\uparrow)(\downarrow)$ it has a tendency to take one electron at a time, resulting in the formation of $\mathrm{O}_{2}{ }^{\bullet-}$, the superoxide radical $(\uparrow \downarrow)(\uparrow)$. Superoxide is capable of participating in reaction sequences to produce other oxygen free radicals-for example, the hydroxyl radical $(\mathrm{OH})$ and hydrogen peroxide $\left(\mathrm{H}_{2} \mathrm{O}_{2}\right)$. Hydrogen peroxide is not a free radical as it has no unpaired electrons-it is, however, an oxidant with good diffusion ability and is classified as a reactive oxygen species, a collective term tha $\vec{b}$ also encompasses oxygen free radicals.

\section{Do we generate oxygen free radicals in health?}

When polymorphonuclear leucocytes engulfo microbes they rapidly consume oxygen. This 'extrarespiration of phagocytosis ${ }^{3}$ or respiratory burst is not used for generating energy by mitochondria令 oxidative phosphorylation, for which the bulk of our inhaled oxygen is used. Why then does it occur?

The oxygen consumption is used by polymorphonuclear leucocytes to produce reactive oxygerf species, which are responsible for killing microbiab pathogens. Two enzyme systems are responsible for this generation of reactive oxygen species: $(a) \stackrel{8}{2} 0$ plasma membrane bound NADPH oxidase systeme incorporating cytochrome $b-245^{4} ;(b)$ the myeloperoxidase system; a haemoprotein located within thes azurophilic granules.

The NADPH oxidase is responsible for generating $\mathrm{O}_{2}{ }^{-}$. The superoxide radical dismutates to formo hydrogen peroxide (reaction 1). This reaction may also be driven more efficiently by the intracellularo enzyme (and radical scavenger) superoxide dismutase. Superoxide also reduces any iron complexes present to the iron(II) state (reaction 2).

$$
\begin{gathered}
2 \mathrm{O}_{2}^{--}+2 \mathrm{H}^{+} \rightarrow \mathrm{H}_{2} \mathrm{O}_{2}+\mathrm{O}_{2} \\
\mathrm{Fe}^{3+}+\mathrm{O}_{2}^{--} \rightleftharpoons\left(\mathrm{Fe}^{3+}-\mathrm{O}_{2}^{--} / \mathrm{Fe}^{2+}-\mathrm{O}_{2}^{-}\right) \rightleftharpoons \mathrm{Fe}^{2+}+\mathrm{O}_{2}(2) \frac{\mathrm{B}}{\text { perferryl species }}
\end{gathered}
$$

This reduction proceeds with the intermediate formation of perferryl species, an iron-oxygen을 complex with a resonance structure intermediate between that of $\mathrm{Fe}^{2+}-\mathrm{O}_{2}^{-}$and $\mathrm{Fe}^{3+}-\mathrm{O}_{2}^{-}$.

Iron(II) ions and hydrogen peroxide react to $N$ generate the hydroxyl radical by the Fenton reaction N (reaction 3).

$$
\mathrm{H}_{2} \mathrm{O}_{2}+\mathrm{Fe}^{2+} \rightarrow \mathrm{OH}^{-}+\mathrm{OH}^{-}+\mathrm{Fe}^{3+}
$$

The hydroxyl radical is so highly reactive that when produced in vivo it reacts with molecules at or withino a few nanometres from its site of production. In 
biological systems iron does not exist in a 'free' state but exists in complexes with phosphate esters (such as ATP and GTP), organic acids (such as citrate and ascorbate), and iron storage/transport proteins (ferritin, lactoferrin, and transferrin). All these complexes of iron, with the probable exceptions of lactoferrin and transferrin, catalyse the free radical degradation of DNA. A biochemical assay for this form of iron has been developed-the 'bleomycin iron' assay. ${ }^{5}$

A major determinant of the cell toxicity of $\mathrm{O}_{2}{ }^{-}$ and $\mathrm{H}_{2} \mathrm{O}_{2}$ is the availability and location of iron to catalyse $\mathrm{OH}$ production. The subsequent site of attack of $\mathrm{OH}^{\circ}$ is determined by the site of the bound iron, so called 'site specific attack'. For example, if iron is bound to membrane lipid, introduction of $\mathrm{H}_{2} \mathrm{O}_{2}$ and $\mathrm{O}_{2}^{\circ-}$ may lead to lipid peroxidation.

There is much debate about the role of the hydroxyl radical in initiating lipid peroxidation in systems containing iron salts. ${ }^{6}$ There have been suggestions that the perferryl complex (reaction 2 ) is the true initiator of peroxidation. The experimental evidence is indirect, however, as the perferryl ion has not been isolated nor has perferryl promoted lipid peroxidation been directly shown.

The myeloperoxidase enzyme is discharged into the phagocytic vesicle by the process of degranulation and reacts with $\mathrm{H}_{2} \mathrm{O}_{2}$ to generate $\mathrm{HOCl}$ and related chloramines. $^{7}$

Evidence for the importance of the generation of reactive oxygen species by polymorphonuclear leucocytes comes from $(a)$ the demonstration that cells deprived of oxygen engulf but do not kill certain microbes efficiently; ${ }^{9}(b)$ the syndrome of chronic granulomatous disease, in which the respiratory burst fails owing to an inherited absence of cytochrome $b-245$, resulting in persistent bacterial infections despite normal opsonisation and phagocytosis. ${ }^{10}$ Organisms are efficiently cleared from the blood and tissues, but the phagocytes continue to carry viable organisms into the reticuloendothelial system. Thus infection is common in lymph nodes, liver, and bone, in addition to the lungs and skin, leading to chronic granulomas. Interestingly, it appears that the myeloperoxidase system is not essential for bacterial killing as large numbers of asymptomatic subjects have been identified whose cells are devoid of this system.

This provides an intriguing paradox: on the one hand, a failure to produce reactive oxygen species causes a syndrome of chronic granuloma formation, while, on the other hand, it is believed that an uncontrolled or inappropriate production of reactive oxygen species leads to inflammation with granuloma formation in rheumatoid arthritis (RA). This quandary is further fuelled by an observation in a patient with chronic granulomatous disease who was injected subcutaneously with urate crystals to assess the inflammatory response. Quite unexpectedly an enormous local inflammatory reaction with a normal acute phase response was seen (Dieppe P, Segal AW, personal communication). Radical reactions are therefore clearly fundamental to human biology, and a failure of the production system causes disease.

\section{But do oxygen free radicals themselves cause disease?}

One potential site for oxidative radical attack is the cell membrane. Composed of polyunsaturated lipids, it is a primary target, and the resultant process of lipid peroxidation-that is, rancidification ${ }^{11}$ causes cell membrane damage. Polyunsaturated lipids (fatty acids) have methylene interrupted unconjugated double bonds. Radical attack at this point abstracts the 'vulnerable' hydrogen atom, causing rearrangement of the double bond and the formation of a conjugated diene radical species. ${ }^{12}$ Diene conjugates can be measured by their characteristic ultraviolet absorbance at $233 \mathrm{~nm}$. Further peroxidation yields conjugated diene hydroperoxides and cytotoxic aldehydes, which can be detected by their reaction with thiobarbituric acid to form a chromophore. ${ }^{13}$ In vivo, lipid peroxides may be produced both enzymically-for example, by the arachidonc acid cascade-and non-enzymically by lipid peroxidation. These two systems may interact as peroxide production will feed back to activate cyclo-oxygenase activity. ${ }^{14}$ Unlike diene conjugate detection, the thiobarbituric acid reaction does not differentiate between prostaglandin metabolites and radical mediated lipid peroxidation products. On the other hand, increased tissue levels of diene conjugates may result from processes other than lipid peroxidation. Therefore it is a requisite that in vivo lipid peroxidation is assessed by several methods.

Exposure of proteins to reactive oxygen species leads to denaturation, loss of function, cross linking, aggregation, and fragmentation. Hydroxyl radical generation at sites of transition metal-ion binding produces localised or site specific damage. ${ }^{15}$ Methionine residues on $\alpha_{1}$-antitrypsin (the primary inhibitor of neutrophil elastase in serum) are oxidised by reactive oxygen species, rendering the molecule biologically inactive. ${ }^{16}$

Radicals also react with carbohydrate polymers and induce fragmentation-for example, the in vitro depolymerisation, mediated by reactive oxygen species, of the glycosaminoglycan hyaluronic acid. This is a primary component of synovial fluid, and such damage results in a drop in viscosity. ${ }^{17}$ 
Single and double strand scission of DNA, together with hydroxylation of constituent bases, are changes characteristic of oxygen radical attack on DNA. Again an important mechanism is site specific hydroxyl radical generation, catalysed by iron bound to cellular DNA. ${ }^{18}$ For example, the reaction of the hydroxyl radical with the DNA base deoxyguanosine results in the formation of 8hydroxydeoxyguanosine. ${ }^{19}$ This adduct causes an increase in the frequency of misincorporation of DNA bases, ${ }^{20}$ suggesting that somatic mutation induced by oxygen radicals could play a part in the induction of autoimmunity and, possibly, carcinogenesis. ${ }^{21}$

\section{Oxygen free radicals and inflammatory synovitis: the evidence}

There is now much evidence both direct and indirect implicating reactive oxygen species in the pathogenesis of inflammatory synovitis. Cells present in the inflamed joint, such as macrophages, neutrophils, lymphocytes, and endothelial cells, all have the ability when isolated and stimulated to produce reactive oxygen species ${ }^{15} 2223$; and when stimulated in the environment of critical biomolecules such as lipids, DNA, proteins, carbohydrates, proteoglycans, and glycosaminoglycans they promote oxidative damage. ${ }^{1724-28}$

Animal studies have shown superoxide dismutase (reaction 1) to have a well established anti-inflammatory effect in several model systems. ${ }^{29}$ Intraarticular superoxide dismutase in RA has been found to be beneficial, implying a pathogenetic role for $\mathrm{O}_{2}{ }^{\bullet-}$, but these data have been criticised. ${ }^{30}$

Several observations suggest a role for iron dependent radical reactions in promoting inflammatory joint disease. Mild nutritional iron deficiency significantly reduces the severity of adjuvant joint inflammation in rats, ${ }^{31}$ while the iron chelator desferrioxamine has been shown to be anti-inflammatory in both Glynn-Dumonde synovitis in guinea pigs, and adjuvant arthritis in rats. ${ }^{32}$ In rheumatoid arthritis the infusion of iron complexes is known to exacerbate synovitis, ${ }^{33}$ and bleomycin iron is detectable in synovial fluid, the concentration correlating loosely with indices of disease activity. ${ }^{34}$ Additional evidence is the development of arthritis in patients with haemochromatosis.

There is evidence linking reactive oxygen species with cartilage damage. It is known that the hydroxyl radical can degrade cartilage, ${ }^{2} \mathrm{HOCl}$ can attack proteoglycans, and $\mathrm{H}_{2} \mathrm{O}_{2}$ inhibits proteoglycan synthesis by cultured bovine articular cartilage. ${ }^{35}$ Injection of the $\mathrm{H}_{2} \mathrm{O}_{2}$ producing enzyme glucose oxidase into rat knees causes severe cartilage damage and chondrocyte death. ${ }^{36}$ Thus a combina tion of degradation and inhibition of synthesis coulकs facilitate cartilage destruction.

Structural proteins within synovial cells are modie fied by reactive oxygen species. Actin is disrupted ${ }^{35^{7}}$ and vimentin $(58000 \mathrm{kD})$ is specifically cleaved by in vitro treatment with hydrogen peroxide to produce $38000 \mathrm{kD}$ fragments. Cleavage is rapid (<two hours $\Phi$ in rheumatoid patients compared with controls (five hours). This susceptibility is reflected in increased structural damage to rheumatoid synovia? cells by reactive oxygen species in vitro, 38 and probably explains the changes in vimentin ultrae structure $^{39}$ and autoantibody production ${ }^{40}$ note产 in vivo. Other studies suggest a relation between these changes and monocyte/macrophage retentio at sites of inflammation. ${ }^{41}$

A notable illustration of the potential proinflamo matory action of reactive oxygen species in arthritis is provided by the condition alcaptonuria, caused bi a defect of the enzyme homogentisate oxidase which is involved in tyrosine metabolism. These patients accumulate homogentisic acid, have pig mented cartilage and connective tissues, and develoo severe inflammatory arthritis. Martin and Batkgffshowed that oxidation of homogentisic acid generageso reactive oxygen species and suggested that promotes the arthropathy. ${ }^{42}$ Magnetic resona imaging of joint cartilage in alcaptonuria $\overline{\text { ha }}$ demonstrated a paramagnetic substance, chemicall identified as melanin, which was shown to have् cytotoxic effects mediated by reactive oxyge species. $^{43}$

In patients with inflammatory joint disease there are abnormalities consistent with oxidative damage? The serum and synovial fluid contain end product of lipid peroxidation, and these are found to correlate with disease activity. ${ }^{34}$ Imunoglobulin $\stackrel{G}{G}$ when exposed to reactive oxygen species develops a characteristic autofluorescence (Ex $360 \mathrm{~nm}$ $\mathrm{Em} 454 \mathrm{~nm}$ ) and forms monomeric and polymerie complexes $^{44}:$ IgG with these characteristics is present in rheumatoid synovial fluid. ${ }^{45} \alpha_{1}$-Antitrypsin is present in rheumatoid synovial fluid in a form consistent with oxidative damage. ${ }^{46}$ In RA, ascorbate concentrations in both synovial fluid and plasma are low and most of that present is in the oxidised dehydroascorbate form. ${ }^{4}$

Oxidative damage mediated by reactive oxygen species requires oxygen, however, and the fact tha建 the oxygen tension in inflammatory synovial fluid is low $^{48}$ might suggest that cells will have a depressed rather than increased ability to generate reactive $e^{+}$ oxygen species. ${ }^{49}$ To address this paradox we have speculated that inflammatory synovitis is an example of hypoxic-reperfusion injury. 


\section{Hypoxic-reperfusion injury: a means of radical production}

Hypoxic-reperfusion injury is a known mechanism of production of reactive oxygen species. In brief, this process, described in detail by McCord, suggests that on the restoration of blood supply after a transient ischaemic event reactive oxygen species are generated by the uncoupling of a variety of intracellular redox systems. ${ }^{51}$ What is the evidence?

It has been shown that transient ischaemic injury to the small bowel of cats results in increased intestinal capillary permeability and albumin clearance. ${ }^{52}$ The increased intestinal capillary permeability that is observed during reperfusion can be blocked in these animals, however, by predosing with the radical scavenging enzymes superoxide dismutase or catalase, or allopurinol, a xanthine oxidase inhibitor. ${ }^{53}$ In this animal model tissue injury is thought to be related to the generation of $\mathrm{O}_{2}^{\circ-}, \mathrm{H}_{2} \mathrm{O}_{2}$, and $\mathrm{OH}$. The effect of ischaemia on myocardial function in various animals has been modified by treatment with superoxide dismutase, catalase, and mannitol, all putative scavengers of reactive oxygen species. 5455

The mechanism for the production of $\mathrm{O}_{2}^{\circ-}$ in ischaemic tissues appears to be effected by changes in purine metabolism within ischaemic cells. During temporary ischaemia low oxygen concentrations halt mitochondrial oxidative phosphorylation, and cellular ATP production becomes dependent on anaerobic glycolysis. This is an inefficient means of ATP production from glucose and leads to raised concentrations of adenosine and of its breakdown products, including hypoxanthine and xanthine, which are the substrates for the xanthine dehydrogenase enzyme system. ${ }^{56}$

Xanthine dehydrogenase is a cytosolic enzyme normally oxidising hypoxanthine and xanthine to uric acid, while using NAD as an electron acceptor. It is located predominantly in capillary endothelium. In ischaemic conditions the enzyme is converted to an oxidase form, which can transfer electrons directly to molecular $\mathrm{O}_{2}$, generating both $\mathrm{O}_{2}{ }^{\circ-}$ and $\mathrm{OH}^{-51}$ Xanthine oxidase is a well used laboratory tool and like the enzyme glucose oxidase is capable of promoting inflammation in animal model systems.

Hypoxic-reperfusion injury has been applied to many disease states, including transient coronary or cerebral ischaemia, ischaemic acute renal failure, and bone transplant damage. ${ }^{58-61}$ Animal models support the view that similar processes should occur in man, but direct evidence has been lacking. We have recently developed a human model that demonstrates hypoxic-reperfusion injury occurring within the inflamed human joint. ${ }^{62}$

\section{Hypoxic-reperfusion injury and inflammatory synovitis: the evidence}

Several physiological and biochemical features present within the inflamed joint suggest that exercise will provide the potential environment for hypoxic-reperfusion injury.

The intra-articular pressure in the normal knee joint of both humans and animals is at or slightly below atmospheric pressure. ${ }^{6364}$ Jayson and Dixon showed that in the normal joint quadriceps contraction produces a subatmospheric pressure. ${ }^{65}$ In contrast, patients with RA had significantly higher resting pressures than control subjects with a simulated effusion of the same volume. ${ }^{63}$ On quadriceps setting patients with RA produced intra-articular pressures as high as $200 \mathrm{mmHg}$, well in excess of the synovial capillary perfusion pressure of $30-60 \mathrm{mmHg} .{ }^{65} \mathrm{We}$ have recently supported these findings, and also shown a dynamic inverse relation between synovial fluid oxygen tension and intraarticular pressure in inflammatory synovitis. ${ }^{62}$

The $\mathrm{Po}_{2}$ in inflamed joints has been measured by several research groups, and it is agreed that inflammatory effusions have lower oxygen tensions than non-inflammatory effusions. ${ }^{48} 6687$ Also, the severity of the hypoxia correlates with the synovial histological findings of synovial cell proliferation, focal necrosis, and focal obliterative microangiopathy. ${ }^{68}$

One determinant of synovial fluid oxygen tension is the blood supply to the synovium. This should be related to the intra-articular pressure as the synovial membrane and joint capsule form a closed environment in which the intra-articular pressure is transmitted directly to the synovial membrane vasculature.

We have recently studied microvascular perfusion dynamics within the synovium of the knee during exercise using laser Doppler flowmetry. In the normal knee there was a negligible reduction of capillary perfusion during exercise. In contrast, exercise of the inflamed knee produced occlusion of the synovial capillary bed for the duration of the exercise. Reperfusion of the synovial membrane occurred when exercise stopped. ${ }^{62}$

Another study has shown that endothelial cells subjected to anoxia/reoxygenation cycles generate superoxide derived hydroxyl radicals, leading to endothelial cell injury. ${ }^{28}$ In this study the radicals were generated by xanthine oxidase, an enzyme system we have previously shown to be present in both normal and diseased synovial tissue. ${ }^{69}$

Thus exercise of the inflamed human knee joint provides the potential pathophysiological environment for the promotion of hypoxic-reperfusion injury. We have recently verified this by demon- 
strating exercise induced oxidative damage to lipids and IgG within the knee joint of patients with inflammatory synovitis. ${ }^{62}$

There is therefore strong evidence to support the hypothesis that the peculiar persistence of synovial inflammation is a consequence of exercise induced, radical promoted hypoxic-reperfusion injury. ${ }^{50}$ What is the corroborating clinical evidence?

Bed rest is a well established treatment of RA. The benefit of isolated joint splintage has been proved, ${ }^{70}$ and systemic and articular rest have been shown to improve RA, both in patients in hospital ${ }^{71}$ and those at home. ${ }^{72}$ Several observations suggest that overuse of a limb increases the severity of RA. ${ }^{73-77}$

A review of publications concerning unilateral neurological lesions leading to unilateral paralysis, involving the upper or lower motor neurone, and the resulting effect on arthritic conditions is illuminating. Jacqueline described the case of a man with a right hemiplegia from childhood who developed severe RA in adult life, confined to the non-hemiplegic side. ${ }^{78}$ Thompson and Bywaters reported four cases in which classical seropositive RA supervened after hemiplegia. ${ }^{79}$ All joints in the completely hemiplegic limbs were spared the onset of arthritis. All four patients developed unilateral RA in their neurologically intact limbs, associated with erosive radiological changes. Two of the patients, however, retained some use of their hemiplegic limbs and subsequently developed RA in these used but hemiplegic limbs, indicating the importance of joint movement in pathogenesis.

Glick reported 12 cases of RA occurring in patients previously paralysed by poliomyelitis. There was almost total sparing of the joints of the paralysed limb(s), both clinically and radiologically. ${ }^{80}$ Sparing of paralysed joints is not confined to $\mathrm{RA}$, similar observations being reported in gout $^{81}$ and osteoarthritis. ${ }^{82}$

Oxygen radical reactions are fundamental to human biology-we are after all aerobes, and oxygen itself is a biradical. Oxygen metabolites have complex interactions with a wide range of biomolecules and are both mediators and modulators of the inflammatory response. Our understanding of the dominant processes involved is rapidly advancing, and novel therapeutic intervention is a realistic possibility.

The Inflammation Group,

P MERRY

Bone and Joint Research Unit.

London Hospital Medical College,

London E1 2AD
References

1 Halliwell B. Oxygen radicals and metal ions: potential anti oxidant intervention strátegies. In: Cross C E, moderator $\Rightarrow$ Oxygen radicals and human disease. Ann Intern Med 1987; 107: 526-45.

2 Halliwell B, Gutteridge J M C. The importance of free radical and catalytic metal ions in human diseases. Mol Aspects Med 1985; 8: 89-193.

3 Baldridge $\mathrm{C} W$, Gerard $\mathrm{R} W$. The extra respiration of phagocytosis. Am J Physiol 1933; 103: 235-6.

4 Rossi F. The superoxide-forming oxidase of phagocytes: nature mechanisms of activation and function. Biochim Biophys Acta 1986; 853: 65-89.

5 Gutteridge J M C, Rowley D A, Halliwell B. Superoxide dependent formation of hydroxy radicals in the presence of iror salts. Detection of 'free' iron in biological systems by using bleomycin-dependent degradation of DNA. Biochem J 1981 을 199: 263-5.

6 Aust S D, Svingen B A. The role of iron in enzymatic lipiopo peroxidation. In: Pryor W A, ed. Free radicals in biology. Vol 5 $\overrightarrow{0}$ New York: Academic Press, 1982: 1-28.

7 Klebanoff S J, Clark R A. The neutrophil: function and clinicab disorders. Amsterdam: North-Holland, 1978: 810.

8 Selveraj R J, Sbarra A J. Relationship of glycolytic and oxidative metabolism to particle entry and destruction in phagocytosing cells. Nature 1966; 211: 1272-6.

9 Mandell G L. Bactericidal activity of aerobic and anaerobiô polymorphonuclear neutrophils. Infect Immun 1974; 9: 337-41응

10 Segal A W. Variations on the theme of chronic granulomatous disease. Lancet 1985 ; i: $1378-82$.

11 Winyard P G, Arundel L A, Blake D R. Lipoprotein oxida佟 and induction of feroxidase activity in stored human extracellowa fluids. Free Radical Research Communications 1988; 5 227-35.

12 Blake D R, Allen R E, Lunec J. Free radicals in biologła systems-a review orientated to inflammatory processes Br Med Bull 1987; 43: 371-85.

13 Satoh K. Serum lipid peroxide in cerebrovascular disorder: determined by a new colorimetric method. Clin Chim Act\$ 1978; 90: 37-43.

14 Warso M, Lands W. Presence of lipid hydroperoxide in humar? plasma. J Clin Invest 1985; 75: 667-71.

15 Winyard P G, Hider R C. Brailsford S, Drake A F, Lunec J? Blake D R. Effects of oxidative stress on some physicochemicat properties of caeruloplasmin. Biochem J 1989; 258: 435-45.

16 Carp H, Janoff A. In vitro suppression of serum elastase inhibitory capacity by reactive oxygen species generated bo phagocytosing polymorphonuclear leucocytes. J Clin Invest 1979; 63: 793-7.

17 Greenwald R A. Moy Wai W. Effect of oxygen free radicals of hyaluronic acid. Arthritis Rheum 1980; 23: 455-63.

18 Loeb L A. James E A. Waltersdorph A M, Klebanoff S J Mutagenesis by the autoxidation of iron with isolated DNA Proc Natl Acad Sci USA 1988; 85: 3918-22.

19 Schraufstatter I. Hyslop P A, Jackson J H, Cochrane C GO Oxidant-induced DNA damage of target cells. J Clin Inves $\bar{T}$ 1988; 82: 1040-50.

20 Kuchino $\mathrm{Y}$, Mori F, Kasai $\mathrm{H}$, et al. Misreading of DNA templates containing 8-hydroxydeoxyguanosine at the modified base and at adjacent residues. Nature 1987; 327: 77-9.

21 Harris G. DNA damage and repair in immunologicaly active cells. Immunology Today 1983; 4: 109-12.

22 Maly F E, Cross A R, Jones O T G, et al. The superoxide generating system of B cell lines. J Immunol 1988; 140: 2334-9

23 Zweier J L. Kuppusamy P, Lutty G A. Measurement of endothelial cell free radical generation. Evidence for a central mechanism of free radical injury in postischaemic tissues. Proc Natl Acad Sci USA 1988; 85: 4046-50.

24 Sevanian A. Hochstein P. Mechanisms and consequences o
C J MORRIS

M GROOTVELD

D R BLAKE 
lipid peroxidation in biological systems. Annual Review of Nutrition 1985; 5: 365-90.

25 Birnboim H C, Kanabus-Kaminska M. The production of DNA strand breaks in human leucocytes by superoxide may involve a metabolic process. Proc Natl Acad Sci USA 1985; 82: 6820-4.

26 Winyard P G, Lunec J, Brailsford S, Blake D R. Action of free radical generating systems upon the biological and immunological properties of caeruloplasmin. Int J Biochem 1984; 16: 1273-8.

27 Gutteridge J M C. Reactivity of hydroxyl and hydroxyl like radicals discriminated by release of thiobarbituric acid-reactive material from deoxy sugars, nucleosides and benzoate. Biochem J 1984; 224: 761-7.

28 Dean R T, Roberts C R, Forni L G. Oxygen-centred free radicals efficiently degrade the polypeptide of proteoglycans in cartilage. Biosci Rep 1984; 4: 1017-26.

29 Michelson A M, Puget K, Jadot G. Anti-inflammatory activity of superoxide dismutases: comparison of enzymes from different sources in different models in rats: mechanism of action. Free Radical Research Communications 1986; 2: 43-56.

30 Greenwald $\mathbf{R}$ A. Therapeutic benefits of oxygen radical scavenger treatments remain unproven. Journal of Free Radicals in Biology and Medicine 1985; 1: 173-7.

31 Andrews F J, Morris C J, Lewis E J, Blake D R. Effect of nutritional iron deficiency on acute and chronic inflammation. Ann Rheum Dis 1987; 46: 859-65.

32 Andrews F J, Morris C J, Kondratowicz G, Blake D R. Effect of iron chelation on inflammatory joint disease. Ann Rheum Dis 1987; 46: 327-33.

33 Winyard P G, Blake D R, Chirico S, Gutteridge J M C, Lunec J. Mechanism of exacerbation of rheumatoid synovitis by totaldose iron-dextran infusion: in vivo demonstration of ironpromoted oxidative stress. Lancet 1987; i: $69-72$.

34 Rowley D A, Gutteridge J M C, Blake D R, Farr M. Halliwell B. Lipid peroxidation in rheumatoid arthritis: thiobarbituric acidreactive material and catalytic iron salts in synovial fluid from rheumatoid patients. Clin Sci 1984; 66: 691-5.

35 Bates E J, Johnson C C, Lother D A. Inhibition of proteoglycan synthesis by hydrogen peroxide in cultured bovine articular cartilage. Biochem Biophys Acta 1985; 838: 221-8.

36 Dabbagh A, Morris C J, Blake D R. Hydrogen peroxideinitiated animal model of acute inflammation. BrJ Rheumatol 1989; 28 (suppl 1): 45.

37 Raghu G, Striker L. Harlan J, Gown A, Striker G. Cytoskeletal changes as an early event in hydrogen-peroxide induced cell injury: a study in A 549 cells. Br J Exp Pathol 1986; 67: 105-12.

38 Marjanovic M, Morris C J, Lunec J, Blake D R. Cytoskeletal changes following free-radical attack. BrJ Rheumatol 1987; 26: (suppl 2): 69.

39 Morris C J, Farr M, Hollywell C A, Walton K W. Ultrastructure of the synovial membrane in inflammatory arthropathies. $J R$ Soc Med 1983; 76: 27-31.

40 Morris C J. Hollywell C A. Scott D L. Auto-antibodies to cytoplasmic filaments in rheumatoid arthritis: a complex pattern of autoimmunity. Br J Rheumatol 1987; 26 (suppl 1): 62.

41 Linder E. Helin H. Chang C M. Edington T S. Complementmediated binding of monocytes to intermediate filaments in vitro. Am J Pathol 1983; 112: 267-77.

42 Martin J P. Batkoff B. Homogentisic acid autoxidation and oxygen radical generation: implications for the aetiology of alcaptonuric arthritis. Journal of Free Radicals in Biology and Medicine 1987: 3: 241-50.

43 Norfray J F. Klingler W G. Menon I A. Persad A. Berger P A. Ainscough M. A paramagnetic agent causing ochronotic arthropathy. Invest Radiol 1988: 23: 609-15.

44 Lunec J. Wakefield A. Brailsford S. Blake D R. Free radical altered IgG and its interaction with rheumatoid factor. In: RiceEvans C. ed. Free radicals, cell damage and disease. London: Richelieu Press. 1986: 241-61.

45 Lunec J. Blake D R. McCleary S J. Brailsford S. Bacon P A.
Self perpetuating mechanisms of immunoglobulin $\mathrm{G}$ aggregation in rheumatoid inflammation. $J$ Clin Invest 1985; 76: 2084-90.

46 Wong P S, Travis J. Isolation and properties of oxidised alpha1-proteinase inhibitor from human rheumatoid synovial fluid. Biochem Biophys Res Commun 1980; 96: 1449-54.

47 Lunec J, Blake D R. Determination of dehydroascorbic acid and ascorbic acid in serum and synovial fluid of patients with rheumatoid arthritis. Free Radical Research Communications 1986; 1: 31-41.

48 Lund-Oleson K. Oxygen tension in synovial fluids. Arthritis Rheum 1970; 13: 769-76.

49 Edwards S W, Hallet M B, Campbell A K. Oxygen radical production may be limited by oxygen concentration. Biochem $J$ 1984; 217: 851-4.

50 Woodruff T, Blake D R, Freeman J, Andrews F J, Salt P, Lunec $\mathrm{J}$. Is chronic synovitis an example of reperfusion injury? Ann Rheum Dis 1986; 45: 608-11.

51 McCord $\mathrm{J} \mathrm{M}$. Oxygen-derived free radicals in postischaemic tissue injury. N Engl J Med 1985; 312: 159-63.

52 Granger D N, Sennett M, McElearney P, Taylor A E. Effett of local arterial hypotension on cat intestinal capillary permeability. Gastroenterology 1980; 79: 474-80.

53 Granger D N, Rutili G, McCord J M. Superoxide radicals in feline intestinal ischaemia. Gastroenterology 1981; 81: 22-9.

54 Schlafer M, Kane P F, Kirsch M M. Superoxide dismutase plus catalase enhance the efficacy of hypothermic cardioplegia to. protect the globally ischaemic heart. J Thorac Cardiovasc Surg 1982; 83: 830-9.

55 Stewart J R, Blackwell W H, Crute S L, et al. Prevention of myocardial ischaemia reperfusion injury with oxygen free radical scavengers. Surgical Forum 1982; 33: 317-20.

56 Jennings R B, Reimer K A, Hill M A. Mayer S E. Total ischaemia in dogs hearts. I. A comparison of high energy phosphate production, utilisation and depletion and of adenine nucleotide catabolism in total ischaemia in vitro. Circ Res 1981: 49: 892-900.

57 Della Corte E, Stirpe F. The regulation of rat liver xanthine oxidase: involvement of thiol groups in the conversion of the enzyme activity from the dehydrogenase (type $D$ ) to the oxidase (type O) and purification of the enzyme. Biochem J 1972; 126: 739-45.

58 Gaudual Y, Duvelleroy M A. Role of oxygen radicals in cardiac injury due to reoxygenation. J Mol Cell Cardiol 1984: 16: 459-70.

59 Cao W, Carney J M, Duchon A, Floyd R A, Chevion M. Oxygen free radical involvement in ischaemia and reperfusion injury to brain. Neurosci Lett 1988: 88: 233-8.

60 Canavese C. Stratta P, Vercellone A. The case for oxygen free radicals in the pathogenesis of ischaemic acute renal failure. Nephron 1988; 49: 9-15.

61 Weiss A P C. Moore J R. Randolph M A. Weiland A J. Preventing oxygen free-radical injury in ischaemic revascularized bone grafts. Plast Reconstr Surg 1988: 82: 486-95.

62 Blake D R. Merry P. Unsworth J, et al. Hypoxic-reperfusion injury in the inflamed human joint. Lancet 1989: i: 289-93.

63 Jayson M I V. Dixon A StJ. Intra-articular pressure in rheumatoid arthritis of the knee. I. Pressure changes during passive joint distension. Ann Rheum Dis 1970; 29: 261-5.

64 Levick J R. An investigation into the validity of subatmospheric recordings from synovial fluid and their dependence on joint angle. J Physiol 1979; 289: 55-67.

65 Jayson M I V. Dixon A StJ. Intra-articular pressure in rheumatoid arthritis of the knee. III. Pressure changes during joint use. Ann Rheum Dis 1970: 29: 401-8.

66 Treuhaft P S. McCarty D J. Synovial fluid pH. lactate. oxygen and carbon dioxide partial pressure in various joint diseases. Arthritis Rheum 1971: 14: 475-84.

67 Richman A I. Su E Y. Ho G. Reciprocal relationship of synovial fluid volume and oxygen tension. Arthritis Rheum 1981: 24: $701-5$. 
68 Falchuk K H, Goetzl E J, Kulka N P. Respiratory gases of synovial fluids. Am J Med 1970; 49: 223-31.

69 Allen R E, Outhwaite J M, Morris C J, Blake D R. Xanthine oxidoreductase is present in human synovium. Ann Rheum Dis 1987; 46: 843-5.

70 Partridge R E H, Duthie J J R. Controlled trial of the effects of complete immobilisation of the joint in rheumatoid arthritis. Ann Rheum Dis 1963; 22: 91-9.

71 Duthie J J R. Medical management and prognosis in rheumatoid arthritis. Scot Med J 1967; 12: 96-106.

72 Smith R D. Bed rest at home for rheumatoid arthritis. Arthritis Rheum 1980; 23: 263-4.

73 Lewis-Faning E. Report on an enquiry into the aetiological factors associated with rheumatoid arthritis. Ann Rheum Dis 1950; 9 (suppl).

74 Soila P. A roentgenological study of asymmetry in rheumatoid arthritis. Acta Rheumatologica Scandinavica 1963; 9: 264.

75 Van Dam G. Radiological aspects of rheumatoid arthritis. The hand. Vol 61. Amsterdam: Excerpta Medica Foundation, $1962 \frac{5}{3}$ 63. (International Congress Series.).

76 Glick E N. Influence of mechanical factors on the rheumatoids wrist. Proceedings of the Royal Society of Medicine 1966; 59: 555.

77 Rotès-Querol J, Roig-Escofet D. Début de l'arthrite rhumatoide Rev Rhum Mal Osteoartic 1968; 35: 21-30.

78 Jacqueline $F$. Un cas de polyarthrite évolutive a localisation contro-laterales d'une hemiplegie. Rev Rhum Mal Osteoartic 1953; 20: 323.

79 Thompson M, Bywaters E G L. Unilateral rheumatoid arthritis following hemiplegia. Ann Rheum Dis 1962; 21: 370-7.

80 Glick E N. Asymmetrical rheumatoid arthritis after poliomyelitis. $\mathrm{Br}$ Med J 1967; iii: 26-9.

81 Glynn J J, Clayton M L. Sparing effect of hemiplegia on tophaceous gout. Ann Rheum Dis 1976; 35: 534-5.

82 Coste F, Forestier J. Hemiplegie et Nodosites d'Heberder Controlaterales. Bulletins et Mémoires de la Société Médicale్ des Hôpitaux de Paris 1935; 51: 772-6. 